\title{
On the diurnal variability in F2-region plasma density above the EISCAT Svalbard radar
}

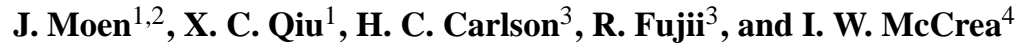 \\ ${ }^{1}$ Department of Physics, University of Oslo, Norway \\ ${ }^{2}$ Visiting professor at Solar-Terrestrial Environmental Laboratory, Nagoya University, Japan \\ ${ }^{3}$ EOARD, 86 Blenheim Crescent, West Ruislip, HA4 7HL UK \\ ${ }^{4}$ Rutherford Appleton Laboratory, Chilton, Didcot, OX11 0QX, UK
}

Received: 5 December 2007 - Revised: 14 May 2008 - Accepted: 10 June 2008 - Published: 6 August 2008

\begin{abstract}
Two long runs of EISCAT Svalbard Radar (ESR), in February 2001 and October 2002, have been analysed with respect to variability in the F2 region peak density and altitude. The diurnal variation in the F2 peak density exhibits one maximum around 12:00 MLT and another around 23:00 MLT, consistent with solar wind controlled transport of EUV ionized plasma across the polar cap from day to night. High density plasma patch material is drawn in through the cusp inflow region independent of IMF $B_{Y}$. There is no apparent IMF $B_{Y}$ asymmetry on the intake of high density plasma, but the trajectory of its motion is strongly $B_{Y}$ dependent. Comparison with the international reference ionosphere model (IRI2001) clearly demonstrates that the model does not take account of the cross-polar transport of F2region plasma, and hence has limited applicability in polar cap regions.
\end{abstract}

Keywords. Ionosphere (Plasma convection; Polar ionosphere) - Magnetospheric physics (Polar cap phenomena)

\section{Introduction}

Within the polar cap there are two different regimes of plasma; the low density background plasma and the high density solar EUV ionized plasma, which convects into the polar cap from sub-auroral latitudes, through the cusp inflow region. Knudsen (1974) suggested that F region plasma convected through the cusp to flow across the polar cap from midday towards night side auroral latitudes, would lead to a tongue of enhanced ionization across the polar cap (TOI).

Correspondence to: J. Moen

(jmoen@fys.uio.no)
Sojka et al. (1994) refined this concept with model studies of segmenting the TOI into commonly observed patches. Foster (1984) mapped the average diurnal pattern of convection and F-region density around the auroral oval and showed enhanced plasma density contours to follow the observed convection contours towards the cusp and polar cap, from lower latitudes in the post noon sector. Foster (1993) showed during magnetic disturbances, in the rest frame of the Earth, post noon plasma can corotate, then stagnate, and then enter return flow towards the cusp inflow region, thereby accumulating large ionization build-up due to unusually long exposure to solar EUV production (storm enhanced density, or SED). Foster (2005) presented observations of complete simultaneous mapping of the plasma density and convection patterns during a major magnetic storm, extending from the SED low latitude dusk source region, clear across the polar cap and into the nightside auroral $\mathrm{F}$ region. While these rare storm events dramatically exhibit the transpolar TOI, we still have limited knowledge about a typical average day.

In this paper we will discuss the diurnal variations in the F2-peak electron density $\left(N_{m} \mathrm{~F}_{2}\right)$ and the altitude of the F2 peak density $\left(h_{m} \mathrm{~F}_{2}\right)$ obtained from two long duration observational runs of field-aligned observations by the EISCAT Svalbard Radar (ESR), in February 2001 and October 2002. We show that the variability in the F2 region plasma density at the magnetic latitude of the ESR is dominated by transport rather than local production. The use of two long continuous data sets, each close to one month in duration, provides a new opportunity to test the IMF $B_{Y}$ influence on the intake of subauroral plasma into the polar TOI region. We demonstrate that the overall intake of patch material is not sensitive to IMF $B_{Y}$. Finally we compare our observations of $\left(N_{m} \mathrm{~F}_{2}, h_{m} \mathrm{~F}_{2}\right)$ with predictions from the

Published by Copernicus Publications on behalf of the European Geosciences Union. 

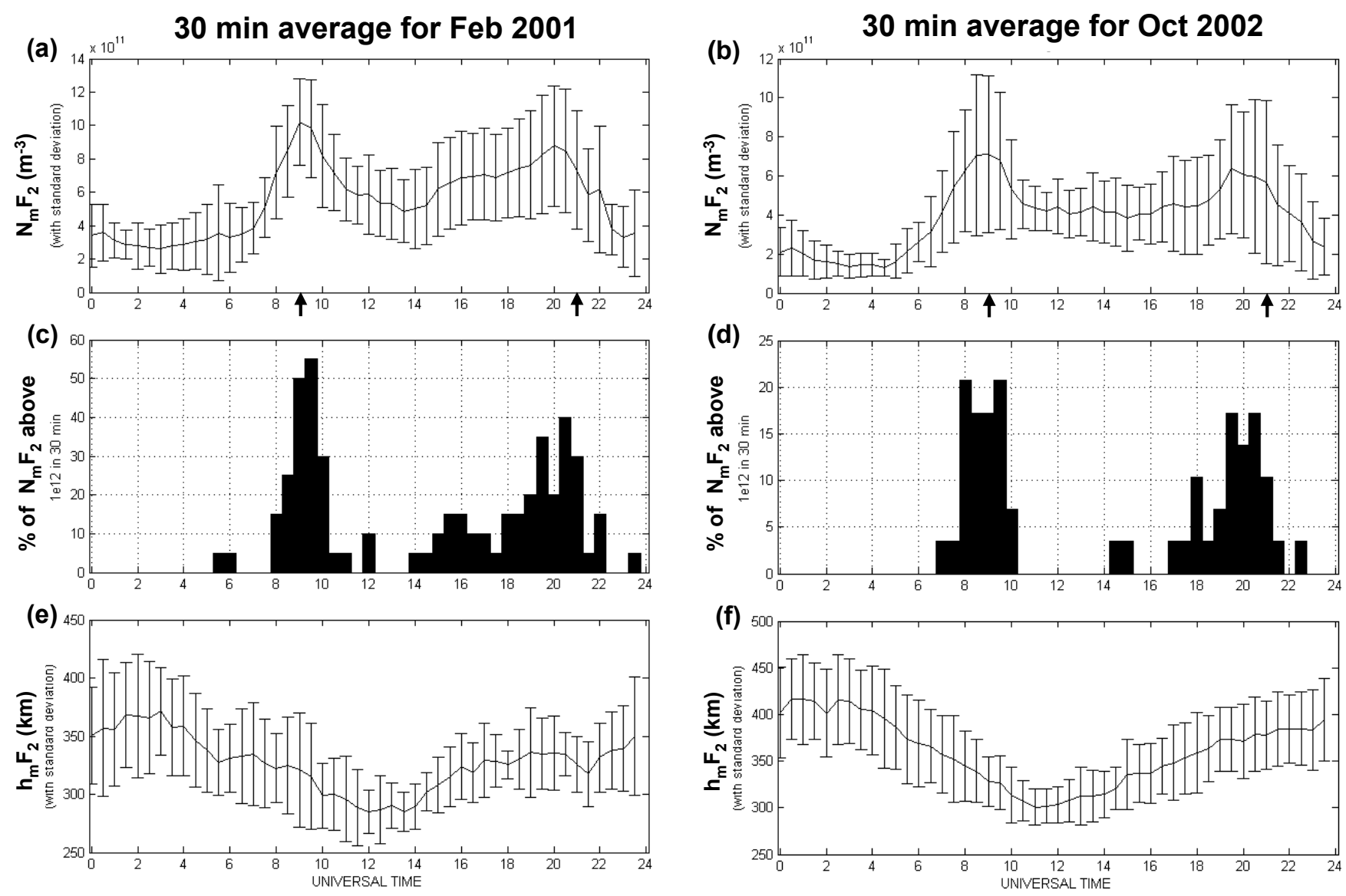

Fig. 1. (a-b) Averaged F2 region peak electron density versus time UT for long duration runs by EISCAT Svalbard Radar in February 2001 and October 2002. Magnetic noon ( 09:00 MLT) and magnetic midnight ( 21:00 MLT) are indicated by arrows on the time axis. The curves represent $30 \mathrm{~min}$ averaged data over each month, and the bars represent one standard deviation in the $N_{m} \mathrm{~F}_{2}$ data. (c-d) The percentage of extreme densities $\left(N_{m} \mathrm{~F}_{2}>10^{-12} \mathrm{~m}^{-3}\right)$ observed in the two data set versus time. (e-f) 30 min averages of altitude of the F2 region peak corresponding to panels (a) and (b). The bars represent one standard deviation spread in $h_{m} \mathrm{~F}_{2}$.

International Reference Ionosphere (IRI2001) model (Bilitza, 2001), which is a widely-used empirical model of the global ionosphere. As earlier demonstrated by Lei et al. (2006) and Zhang et al. (2007) there are large discrepancies between the IRI-model and the ESR measurements, but they did not discuss any reason for it. These differences arise because the IRI model does not account for the transport of solar EUV ionized plasma across the polar cap from day to night, which is a well established phenomenon. The underlying philosophy is to avoid risk of inadequate theory or modelling by building empirically on observational data bases.

\section{Instrumentation}

The EISCAT Svalbard Radar (ESR) is located at Longyearbyen $\left(78.15^{\circ} \mathrm{N}, 16.03^{\circ} \mathrm{E}\right)$, corresponding to $75.1^{\circ}$ MLAT. The ESR consists of two parabolic dish antennas, a 32-m fully steerable dish and a 42-m dish fixed along the magnetic field line. ESR provides altitude profiles of the four primary parameters: electron density, electron temperature, ion temperature and ion velocity $\left(N_{e}, T_{e}, T_{i}\right.$ and $\left.v_{i}\right)$. For this study we use 2 min electron density profiles from the $42 \mathrm{~m}$ antenna, downloaded from the EISCAT data archive at the Rutherford Appleton Laboratory, for two long runs from February 2001 and October 2002. The typical spatial resolution of these data is $3 \mathrm{~km}$ between 90 and $150 \mathrm{~km}$ altitude, $6 \mathrm{~km}$ from 150 to $220 \mathrm{~km}, 12 \mathrm{~km}$ from 220 to $350 \mathrm{~km}$ and $36 \mathrm{~km}$ above $350 \mathrm{~km}$. In October 2002, the radar was operated continuously for 28 days except for a few brief interruptions. The February 2001 data set comprised 19 days of near-continuous operation.

The Interplanetary magnetic field (IMF) and plasma parameters of the solar wind were obtained from the ACE spacecraft (Chiu et al., 1998) located near the L1 point. In this paper we have used data from the magnetic field experiment (MAG; Smith et al., 1998) and solar wind velocity data from the Solar Wind Electron Proton Alpha Monitor (SWEPAM; McComas, 1998) to estimate the time delay between ACE and the magnetopause. 
(a)

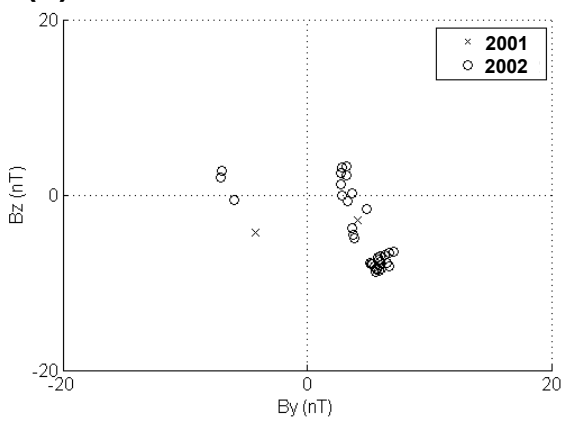

(b)

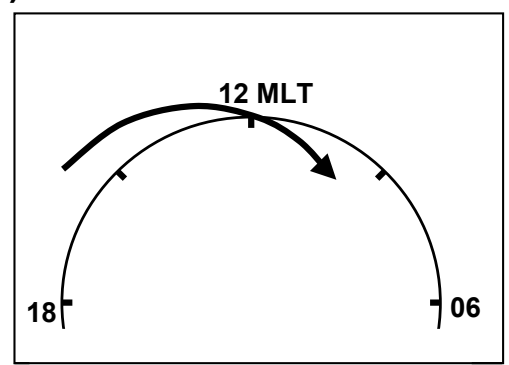

(c)

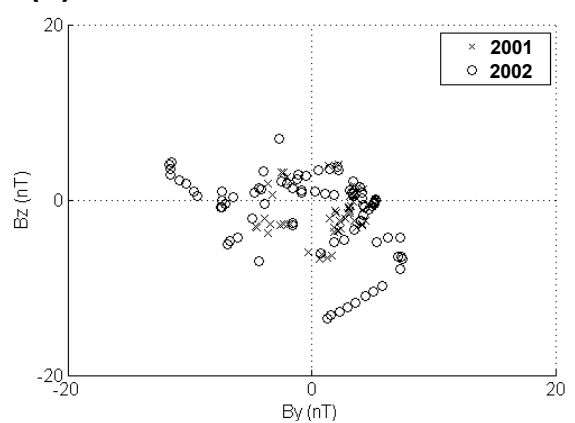

(d)

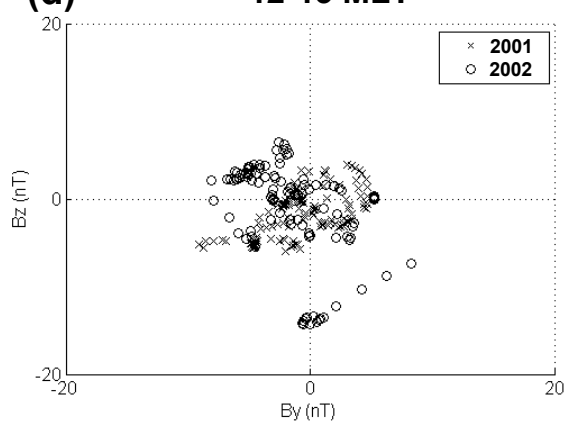

(e)

13-14 MLT

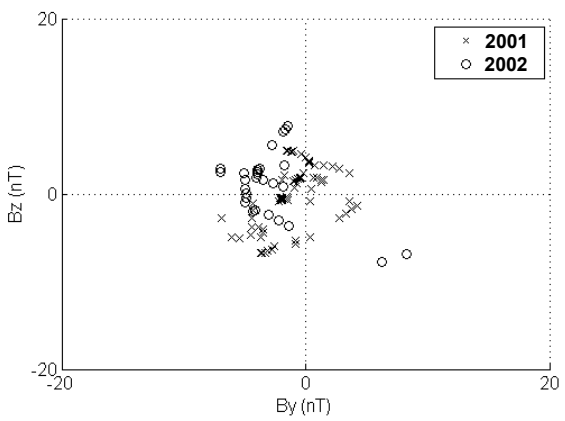

(f)

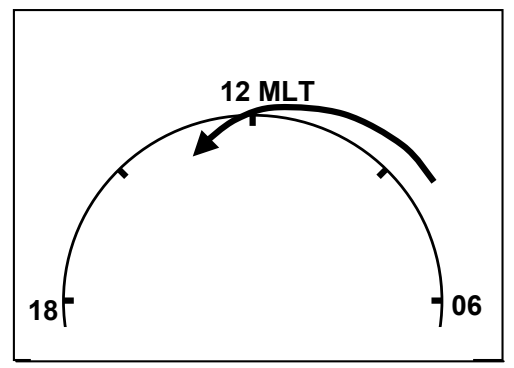

Fig. 2. Panels (a), (c), (d) and (e) represent IMF $B_{Y} / B_{Z}$ scatter plots for the occurrence of extreme values of $N_{m} \mathrm{~F}_{2}$. There is a clear IMF $B_{Y}$ asymmetry in prenoon (10:00-11:00 MLT) and postnoon (13:00-14:00 MLT) that can be explained by transport of high density plasma away from noon as schematically illustrated in panels (b) and (f).

\section{Analysis method and results}

The main objective is to study the diurnal variations in the $\mathrm{F} 2$ region electron density. Electron density values $>5 \times 10^{12} \mathrm{~m}^{-3}$ are considered unphysical and were removed. These appeared mostly as single data points and mainly corresponded to artefacts due to echoes from hard targets and/or poor fits in the data analysis. The peak F-region density $N_{m} \mathrm{~F}_{2}$ and the peak height $h_{m} \mathrm{~F}_{2}$ were identified for every altitude profile. In order to characterize the diurnal variation in $N_{m} \mathrm{~F}_{2}$, the data set for each month was sorted into 48 half hour bins, such that for the month of October 2002, with 28 days of operation, each half-hour bin contains a maximum of 420 values for both magnitude and altitude (28 times 15 data points per $30 \mathrm{~min}$ ). The full curve in the upper two panels of Fig. 1 ( $\mathrm{a}$ and $\mathrm{b}$ ) shows the median values of $N_{m} \mathrm{~F}_{2}$ for each half hour bin plotted as function of universal time (UT) for February 2001 and October 2002, respectively. Please note different scales on the vertical axes. The histograms in Fig. $1 \mathrm{c}$ and d present the percentage of data dumps within the 30-min time intervals when $N_{m} \mathrm{~F}_{2}$ exceeded $1 \times 10^{12} \mathrm{~m}^{-3}$, later referred to as extreme values. The curves in the bottom two panels (Fig. 1e and f) represent the average $h_{m} \mathrm{~F}_{2}$ values corresponding to $N_{m} \mathrm{~F}_{2}$ in panels (a) and (b), respectively. The bars superimposed on each curve represent one standard deviation spread within each $30 \mathrm{~min}$ data bin.
The $N_{m} \mathrm{~F}_{2}$ curves in Fig. 1a and b both exhibit a double peak, a daytime peak around 09:00 UT and a nighttime peak between 19:30-20:00 UT. Magnetic noon at Longyearbyen occurs around 08:50 UT, so the daytime peak is very close to 12:00 MLT, while the nighttime peak corresponds to $\sim 23: 00$ MLT. Figure 1e and f shows a pronounced minimum in $h_{m} \mathrm{~F}_{2}$ between 11:00 and 12:00 UT. Local geographic noon in Longyearbyen is $\sim 11: 00 \mathrm{UT}$.

From Fig. 1c and d it is seen that extreme densities were recorded in $50 \%$ and $17 \%$ of the 2-min data dumps around the noon peaks of February 2001 and October 2002, respectively. This high density plasma represents transport of solar EUV ionisation into the polar cap. It is therefore interesting to check whether the dusk cell is more responsible for the intake of high density plasma than the dawn cell. Figure 2 displays scatter diagrams of $B_{Y}$ vs. $B_{Z}$ for the occurrence of the $N_{m} \mathrm{~F}_{2}$ extreme values. The IMF value attributed to each extreme density represents a 20-min average backward in time from when the event was sampled. This allows some time for plasma to convect from the high-density source region to the radar under solar wind control. IMF $B_{Y}$ positive (negative) imposes a postnoon (prenoon) shift of the cusp inflow region (Ruohoniemi and Greenwald, 2005), and eventual intake of high density plasma there will be swept westward into prenoon sector (eastward into postnoon) as illustrated in Fig. 2b (Fig. 2f). With a zonal speed of $0.5-1 \mathrm{kms}^{-1}$ it will 
take from $7.5-15 \mathrm{~min}$ to travel $1 \mathrm{~h}$ in MLT at 75 MLAT. We tried 10, 20 and 30 min delay time and the IMF $B_{Y}$ asymmetry features did not change. As indicated on the top of each diagram, the observations from 10:00-14:00 MLT (07:0011:00 UT) are binned in $1 \mathrm{~h}$ intervals. The occurrences of extreme densities in the 10:00-11:00 MLT sector were predominantly for IMF $B_{Y}$ positive, while the extreme densities in the 13:00-14:00 MLT sector occur predominantly for IMF $B_{Y}$ negative.

\section{Discussion}

The $N_{m} \mathrm{~F}_{2}$ curves in Fig. 1a and b, with one maximum near magnetic noon and one maximum near magnetic midnight, are consistent with systematic intake of solar EUV ionized plasma in the cusp inflow region, and subsequent transport across the central polar cap into the midnight sector. Figure 3 illustrates how Svalbard was situated under the twin cell polar cap circulation pattern near noon and near midnight on 22 October 2002. The SuperDARN convection map in Fig. 3a was taken at 10:00 UT and represents a situation dominated by IMF $B_{Y}$ negative. The large morning cell swept high density plasma duskward over the radar located $\sim 13: 00$ MLT. Figure $3 b$ illustrates exit flow over Svalbard. There is a notable shift in the exit region towards pre midnight.

Although Svalbard is located under the statistical auroral oval at daytime, the cusp location may vary within the range $\sim 70-79$ MLAT (Sandholt et al., 1998). A significant fraction of the daytime F-region electron density profiles has certainly been augmented by magnetosheath electrons in the $100 \mathrm{eV}$ range (Newell and Meng, 1988). However modelling studies suggest this would only modestly enhance midday plasma densities and little impact $h_{m} \mathrm{~F}_{2}$ (Millward et al., 1999). Further, it is very unlikely that extreme densities larger than $1 \times 10^{12} \mathrm{~m}^{-3}$ (Fig. 1c and d) could have been produced locally. Millward et al. (1999) estimated a maximum electron density near $300 \mathrm{~km}$ of almost $1 \times 10^{12} \mathrm{~m}^{-3}$ for an assumed convection path that resulted in longer exposure of the flux tube to the electron and ion precipitation than generally attributed to reconnection events. The density value obtained is therefore likely to be an overestimate for the observed $N_{m} \mathrm{~F}_{2}$ peak value, although density enhancements of $\sim 6 \times 10^{11} \mathrm{~m}^{-3}$ are entirely possible. We therefore conclude that the $N_{m} \mathrm{~F}_{2}$ peak around magnetic noon represents solarEUV ionized plasma being transported into the polar cap.

The 3-4h wide region of high-density plasma intake around noon (Fig. 1a-d) is consistent with the width of the cusp intake region (e.g. Foster et al., 1984). During IMF $B_{Z}$ north conditions, the ESR may be situated inside or outside the polar cap. If the radar is situated inside the polar cap during IMF $B_{Z}$ north, lobe reconnection may stir around high density plasma that has previously been taken into the polar cap. If the radar is situated on the equatorward side of a contracted polar cap, the radar may probe solar EUV ionized plasma at sub-auroral latitudes.

At night ESR is usually situated well inside the polar cap most of the time, except during the substorm expansion phase when the poleward auroral boundary sometimes leaps across the radar site in Longyearbyen (Lorentzen et al., 2004). The night time peak in $N_{m} \mathrm{~F}_{2}$ in Fig. $1 \mathrm{a}-\mathrm{b}$ is centred on 20:00 UT=23:00 MLT. The night peak around 20 UT was observed by an ionosonde in Longyearbyen in 1957 (cf. Fig. 1 in King et al., 1968). King et al. (1968) attributed it to pressure gradient driven flow at F-region altitudes, from the highest pressure region near Equator at 14:00 LT along all great-circle paths including those over the geographic pole, towards the lowest pressure region near equator at 02:00 LT (cf. Fig. 2 in King et al., 1968). According to this neutral wind pattern, at 21:00 LT at $78^{\circ}$ geographic latitude, there will be a component of southward flow and a lift of ionospheric plasma along the magnetic field line corresponding to that. However, based on systematic observations by low-altitude polar orbiting satellites the IMF control of polar cap convection became established a couple of decades later (Heelis et al., 1982; Heelis, 1984; Heppner and Maynard, 1987), and the climatology of polar cap convection has recently been mapped out in greater detail by SuperDARN (Ruohoniemi and Greenwald, 2005). In a statistical study of $630.0 \mathrm{~nm}$ airglow patches from Svalbard, Moen et al. (2007) documented a similar pre-midnight shift in the $630.0 \mathrm{~nm}$ patch occurrence rate as for the $N_{m} \mathrm{~F}_{2}$ peak presented here. $60 \%$ of the optical patches were observed to exit the polar cap between 22:00 and 01:00 MLT. They found the pre-midnight shift to be consistent with a statistical plasma flow pattern representative of the averaged IMF conditions yielding their data set (Ruohoniemi and Greenwald, 2005). It is noticed from Fig. 1c-d that a major fraction of extreme densities was sampled between 19:00-22:00 UT, which corresponds to the same period, $\sim 22: 00-01: 00$ MLT.

There is a remarkably large spread in $N_{m} \mathrm{~F}_{2}$ and $h_{m} \mathrm{~F}_{2}$, as demonstrated by the standard deviation bars in Fig. 1. The error bar on any individual $N_{e}$ measurement is only a few percent. Therefore, the variability in $N_{m} \mathrm{~F}_{2}$ represents real fluctuations reminding us that the plasma is highly structured and/or that the flow path of high density plasma within the polar cap is highly variable.

The scatter diagrams in Fig. 2a (10:00-11:00 MLT) and Fig. 2e (13:00-14:00 MLT) demonstrate a clear IMF $B_{Y}$ control on the dawn-dusk asymmetry in the MLT occurrence of extreme densities with their occurrence in the 10:0011:00 MLT sector being biased toward IMF $B_{Y}$ positive, and that in the 13:00-14:00 MLT sector being biased toward IMF $B_{Y}$ negative. The chance for magnetopause reconnection and new intake of high density plasma, possibly leading to patch formation, increases for IMF $B_{Z}$ negative. Hence, for IMF $B_{Z}<0$ this asymmetry can be explained as an IMF $B_{Y}$ control of the east-west movement of newly open flux over the radar in the prenoon sector for IMF $B_{Y}$ positive and in the 


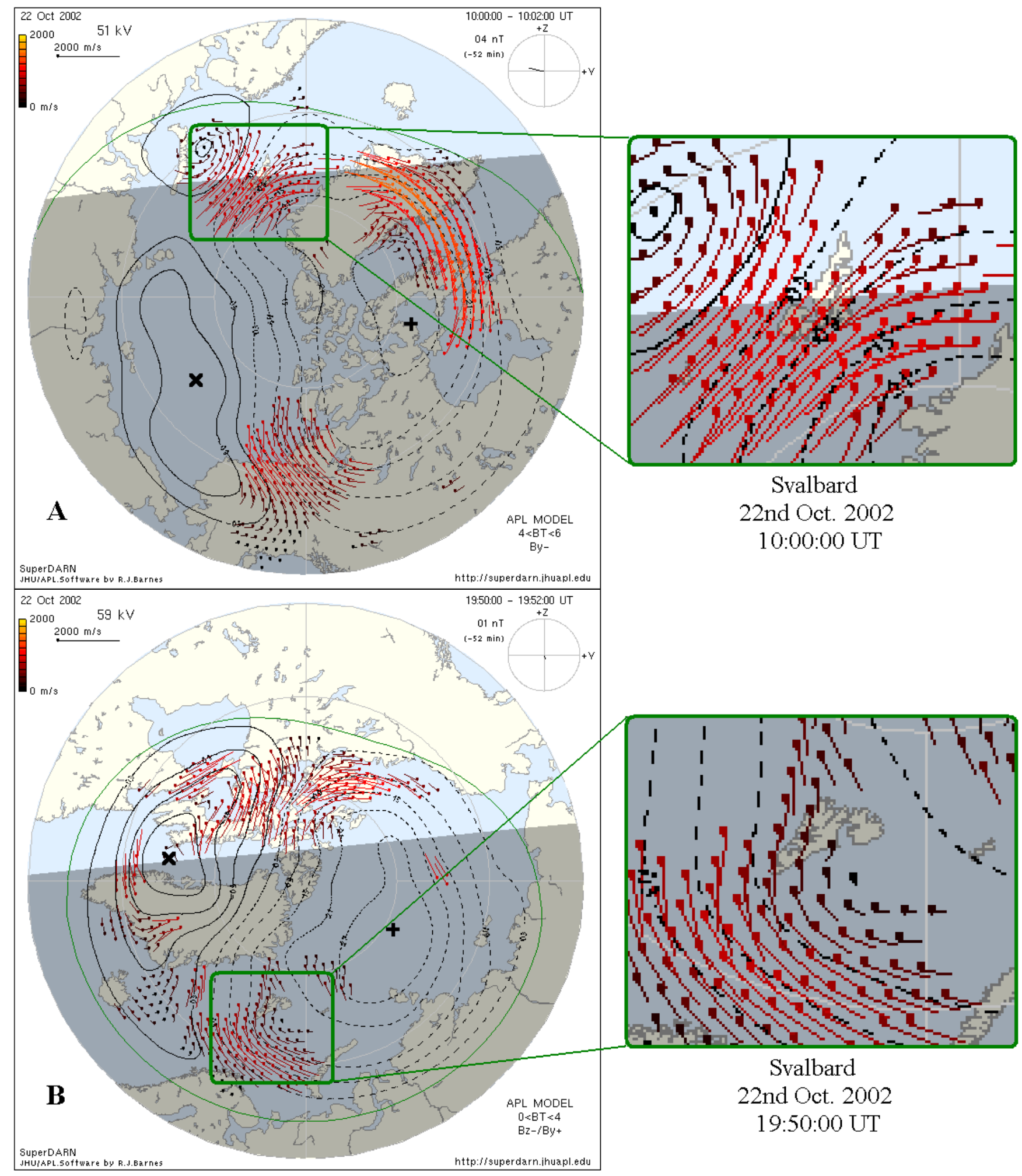

Fig. 3. Illustration of Svalbard's location under, (a) the intake of Solar EUV ionized plasma near noon, and (b) plasma streaming out of the polar cap near midnight. 

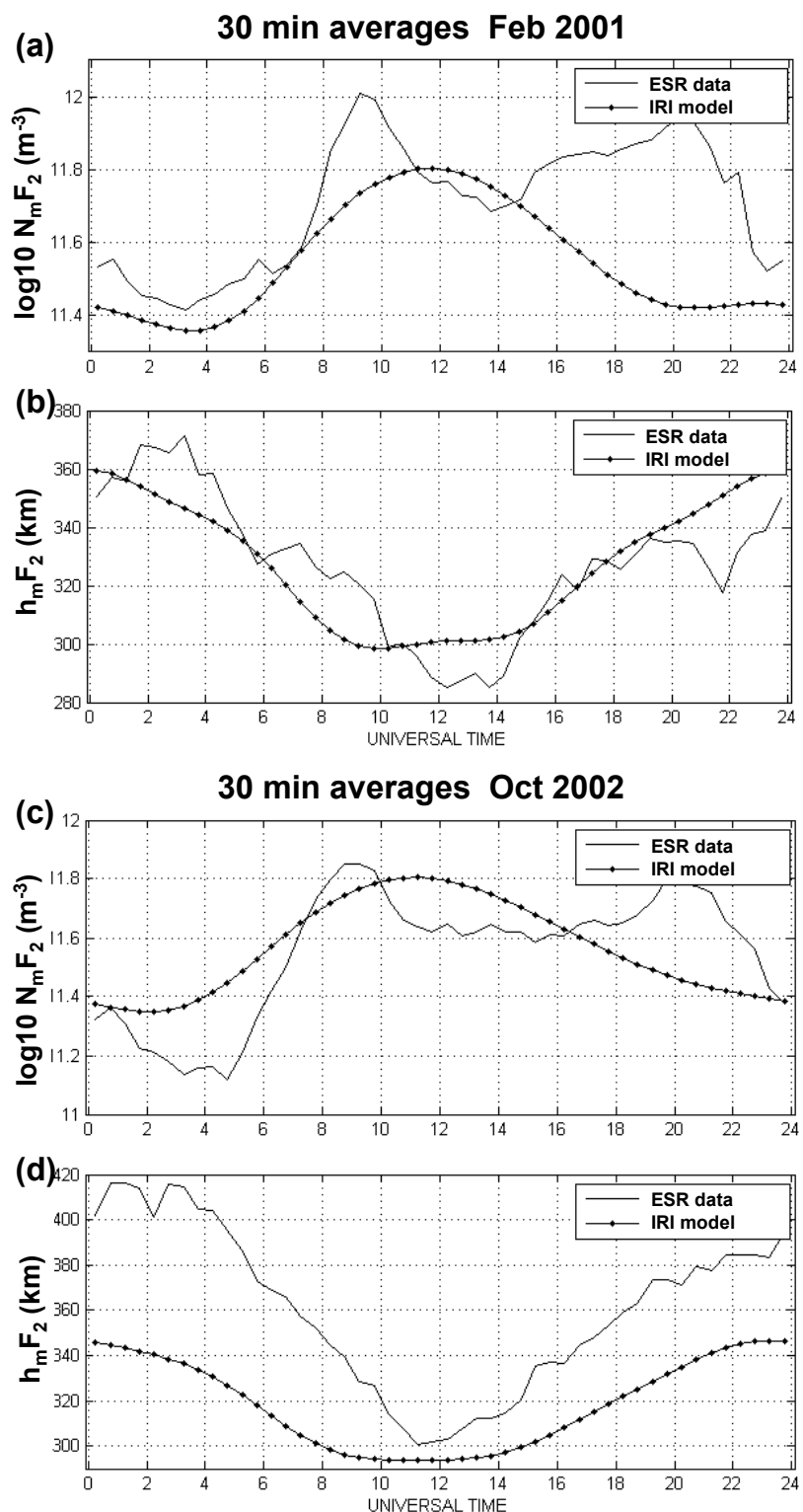

Fig. 4. (a) A comparison between averaged $N_{m} \mathrm{~F}_{2}$ data derived from ESR (full line) and the corresponding values from the IRI2001 model (full line with dots), for the month of February 2001. (b) ESR and IRI model curves of $h_{m} \mathrm{~F}_{2}$ corresponding to the $N_{m} \mathrm{~F}_{2}$ density curves in panel (a). (c-d) Similar to (a-b) but for October 2002.

postnoon for IMF $B_{Y}$ negative, as illustrated in the schematics in Fig. 2b and f. No such asymmetry is seen for the two hours around magnetic noon (Fig. 2c-d; 11:00-13:00 MLT), where it appears that the intake of high density plasma/patch material has no clear dependence on IMF $B_{Y}$ polarity. Recently Moen et al. (2007) presented a statistical distribution of $630.0 \mathrm{~nm}$ airglow patches at night from which they concluded that high-density plasma populates the morning cell as well as the evening convection cell.
Figure 4 demonstrates the comparison between the $N_{m} \mathrm{~F}_{2}$ and $h_{m} \mathrm{~F}_{2}$ values derived from the ESR data and the IRI model ionosphere. We used the IRI-2001 model available on SPDF Modelweb. It was operated in default mode with the STORM model on for the geographic position of the ESR site. The model $N_{m} \mathrm{~F}_{2}$ curves with dots in panels (a) and (c) peak around local geographic noon, while the observed $N_{m} \mathrm{~F}_{2}$ peaks at magnetic noon and one hour pre midnight. Modelled and observed $h_{m} \mathrm{~F}_{2}$ in panels (b) and (c) both display a minimum near geographic noon, i.e. when the observing site is closest to the source of solar EUV ionization. This comparison illustrates clearly that the IRI values represent an extrapolation of data from latitudes where transport of $\mathrm{F} 2$ region plasma is less important and hence the model fails to represent cross-polar transport of plasma, which is a well established physical phenomenon controlled by IMF. The modelled $\log N_{m} \mathrm{~F}_{2}$ peaks at 11.8 for both February 2001 and October 2002, while the measured noon values are 12 and 11.85 , respectively, i.e. a discrepancy of measured relative to model peak density of $90 \%$ in February 2001 while $7 \%$ in October 2002. An explanation for the large discrepancy in February 2001 has yet to be found, but it may well be related to F-region dynamics and transport effects as well.

\section{Summary and concluding remarks}

Two separate months of continuous operation of the EISCAT Svalbard Radar (ESR) observing along the magnetic field line have been analysed with respect to the variability in the $\mathrm{F} 2$ region peak. The major results are as follows:

1. The diurnal variation in the F2 region peak density displays one maximum located almost exactly at 12:00 MLT and one around 23:00 MLT, consistent with cross-polar transport of solar EUV ionized plasma.

2. High density plasma patch material is drawn into the polar cap independent of IMF $B_{Y}$, although its trajectory is strongly dependent on IMF $B_{Y}$.

3. The IRI model does not account for the cross-polar transport of $\mathrm{F} 2$ region plasma, which is the dominating factor in polar cap plasma dynamics.

In order to parameterize the intake region of Solar EUV ionized plasma and transport across the polar cap, we recommend that future ionosphere models make use of the same ordering parameters that Ruohoniemi and Greenwald (2005) introduced for the classification of convection patterns; i.e. IMF, seasonal and universal time factors. The data resulting from the continuous operation of the ESR during the IPY will provide a unique resource for such an effort. To put a scale on the improvement that could be realized in the IRI model by such an approach, midnight values of $N_{m} \mathrm{~F}_{2}$ peak would be replaced by values comparable to noon values, and October values (but not February) of $h_{m} \mathrm{~F}_{2}$ would be increased 
$40-60 \mathrm{~km}$ in height for over half the diurnal cycle (the local darkness period when transport is most important). In February 2001 the measured noon $N_{m} \mathrm{~F}_{2}$ peak was $90 \%$ larger than IRI2001 model value for yet an unknown reason.

Acknowledgements. EISCAT is an international association supported by research organisations in China (CRIRP), Finland (SA), France (CNRS, till end 2006), Germany (DFG), Japan (NIPR and STEL), Norway (NFR), Sweden (VR), and the United Kingdom (STFC). We thank the ACE Science Center and the ACE MAG and SWEPAM instrument teams for providing data from the ACE space craft. We acknowledge the SPDF Modelweb for making the IRI 2001 model available, and The Johns Hopkins University Applied Physics Laboratory for providing web access to SuperDARN convection maps. Financial support has been provided by the Norwegian Research Council, AFOSR task 2311AS, and Solar-Terrestrial Environment Laboratory, and Nagoya University.

Topical Editor K. Kauristie thanks K. Hosokawa and S. E. Pryse for their help in evaluating this paper.

\section{References}

Bilitza, D.: International Reference Ionosphere 2000, Radio Sci., 36, 261-275, 2001.

Chiu, M. C., Von-Mehlem, U. I., Willey, C. E., et al.: ACE spacecraft, Space Sci. Rev., 86, 257-284, 1998.

Foster, J. C.: Ionospheric signatures of magnetospheric convection, J. Geophys. Res., 89, 855-865, 1984.

Foster, J. C.: Storm-time plasma transport in middle and high latitudes, J. Geophys. Res., 98, 1675-1689, 1993.

Foster, J. C., Coster, A. J., Erickson, P. J., et al.: Multiradar observtaions of the polar tonque of ionization, J. Geophys. Res., 110, A09S31, doi:10.1029/2004JA010928, 2005.

Heelis, R. A., Lowell, J. K., and Spiro, R. W.: A model of the high-latitude ionosphere convection pattern, J. Geophys. Res., 87, 6339-6345, 1982.

Heelis, R. A.: The effects of interplanetary magnetic field orientation on dayside high-latitude ionospheric convection, J. Geophys. Res., 89, 2873-2880, 1984.

Heppner, J. P. and Maynard, N. C.: Empirical high-latitude electric field models, J. Geophys. Res., 92, 4467-4490, 1987.
King, J. W., Kohl, H., Preeoe, D. E., and Seabrook, C.: An explanation of phenomena occurring in the high-latitude ionosphere at certain Universal Times, J. Atmos. Terr. Phys., 30, 11-23, 1968.

Knudsen, W. C.: Magnetospheric convection and the high-latitude F2 ionosphere, J. Geophys. Res., 79, 1046-1055, 1974.

Lei J., Liu, L., Wan, W., Zhang, S.-R., and van Eyken, A. P.: Comparison of the first long-duration IS experiment measurements over Millstone Hill and EISCAT Svalbard radar with IRI2001, Adv. Space Res., 37, 1102-1107, 2006.

Lorentzen, D. A., Shumilov, N., and Moen, J.: Drifting airglow patches in relation to tail reconnection, Geophys. Res. Lett., 31, L02806, doi:10.1029/2003GL017785, 2004.

McComas, D. J., Bame, S. J., Barker, P., Feldman, W. C., Phillips, J. L., Riley, P., and Griffee, J. W.: Solar Wind Electron Proton Alpha Monitor (SWEPAM) for the Advanced Composition Explorer, Space Sci. Rev., 86, 563-612, 1998.

Millward, G. H., Moffett, R. J., Balmforth, H. F., and Roget, A. S.: Modelling the ionospheric effects of ion and electron precipitation in the cusp, J. Geophys. Res., 104, 24 603-24 612, 1999.

Moen, J., Gulbrandsen, N., Lorentzen, D. A., and Carlson, H. C.: On the MLT distribution of F-region polar cap patches at night, Geophys. Res. Lett., 34, L14113, doi:10.1029/2007GL029632, 2007.

Newell, P. T. and Meng, C.-I.: The cusp and the cleft/boundary layer: low-altitude identification and statistical local time variation, J. Geophys. Res., 93, 14 549-14 556, 1988.

Ruohoniemi, J. M. and Greenwald, R. A.: Dependencies of high-latitude plasma convection: Consideration of interplanetary magnetic field, seasonal and universal time factors in statistical patterns, J. Geophys. Res., 110, A09204, doi:10.1029/2004JA010815, 2005.

Sandholt, P. E., Farrugia, C. J., Moen, J., Noraberg, Ø., Lybekk, B., Sten, T., and Hansen, T. L.: A classification of dayside auroral forms and activities as a function of IMF orientation, J. Geophys. Res., 103, 23 325-23 345, 1998.

Sojka, J. J., Bowline, M. D., and Schunck, R. W.: Patches in the polar cap ionosphere: UT and seasonal dependence, J. Geophys. Res., 99, 14 959-14 970, 1994.

Smith, C. W., L'Heureux, J., Ness, N. F., Acuna, M. H., Burlaga, L. F., and Scheifele, J.: The ACE magnetic fields experiment, Space Sci. Rev., 86, 613-632, 1998.

Zhang, S.-R., Holt, J. M., Bilitza, D. K., et al.: Multiple-site comparisons between models and incoherent scatter radar and IRI, Adv. Space Res., 39, 910-917, 2007. 